\title{
Wind energy system and efficient deployment in Owerri via distributed generation scheme
}

\author{
Onyema Isdore Akwukwaegbu, Fabian Izundu Izuegbunam \\ Department of Electrical and Electronic Engineering, Federal University of Technology, P. M. B. 1526, Owerri, Nigeria \\ Email address: \\ isdoreonyema@gmail.com (O. I. Akwukwaegbu), fabizu2000@yahoo.com (F. I. Izuegbunam)
}

\section{To cite this article:}

Onyema Isdore Akwukwaegbu, Fabian Izundu Izuegbunam. Wind Energy System and Efficient Deployment in Owerri via Distributed Generation Scheme. Science Journal of Energy Engineering. Vol. 2, No. 3, 2014, pp. 18-24. doi: 10.11648/j.sjee.20140203.11

\begin{abstract}
Wind energy is one of the fastest growing technologies in the energy generation industry nowadays. The erratic and epileptic state of power supply in Nigeria resulting from insufficient generation to meet the load demands, and issues about global warming is of great concern to all. This has led to load shedding; blackout in some parts of the country lasting for hours, closure of some industries due to high operational cost. However the nation is currently diversifying its power generation capabilities through distributed generation using renewable resources. In order to ameliorate the situation, and to curb the global warming challenge, deployment of distributed generation (DG) using wind for electricity generation has become a novel idea. This is so because wind is abundantly available for all hours of the day and the resource is environmentally friendly. This paper therefore evaluated the wind energy potential of Owerri using the available data; considered how best it could be utilized to generate electricity through stand alone scheme and integration with the utility grid for most efficient operation.
\end{abstract}

Keywords: Distributed Generation, Wind Speed, Wind Turbine, Wind Farm, Wind Power Integration, Grid

\section{Introduction}

Energy has a major impact on every aspect of our socioeconomic life. It plays a vital role in the economic, social and political development of our nation. As a matter of fact, it has been established that the difference between the developed and developing nations of the world today lies in their levels of energy generation and utilization. Despite the abundance of energy resources in Nigeria, the country is still in short supply of electrical power. Less than half of the nation's over 150 million has access to grid electricity [1]. Even the electricity supply to the consumers that are connected to the grid is erratic due to insufficiency in generation to meet the ever growing demand for electric energy. Beside the insufficiency in production, due to dilapidated nature of our transmission lines as a result of poor maintenance, a very high percentage of the transmitted power is lost during conveyance to the endusers [2]. The end result of this is inevitable load shedding by power system operators in order to ensure equitable share of the available power. There is therefore need to harness renewable energy potential (such as wind, solar etc.) for reliable power supply in Nigeria.

\subsection{State-of-the-Art Distributed Generation Technology}

Distributed generation (DG) is a method of generating electricity on a small scale from renewable and nonrenewable energy sources [3]. DG plants are modular in nature and are often referred to as packets of generation units. They are usually located close to the power end-users, and serve as alternative to or enhancement of the traditional electric power system. They could produce power in the typical range of $3 \mathrm{~kW}$ to $10,000 \mathrm{~kW}$.

The wind turbine converts the energy present in the wind into electrical energy, which is fed into the electricity supply system. The basic components of the wind turbine and their functions include:

\section{(a) Rotor and Rotor Blades}

The rotor equipped with rotor blades converts the energy in the wind into rotary mechanical movement / shaft energy. The blades capture the wind energy, spinning a generator in the nacelle.

\section{(b) Nacelle with Drive Train}

The nacelle houses a drive train, which usually includes a gearbox and a generator. The gearbox converts the rotor motion of $18-50 \mathrm{rpm}$ into the approximately $1500 \mathrm{rpm}$ required by the generator. The gearbox thus takes on the 
task of matching the slow-moving rotor and the fastmoving generator, and generally has several steps to cover for various wind conditions.

As the generator spins, electricity is produced. Usually, doubly fed induction generators are used for commercial wind farm projects.

\section{(c) Electronic Equipment}

The electronic equipment of a wind turbine is composed of the generator, the system for the grid in-feed of the electricity and various sensors.

The sensors for measuring temperature, wind direction, wind speed and so on can be found in and around the nacelle, assist in turbine control and monitoring.

The conversion mechanism is as illustrated in Fig. 1.

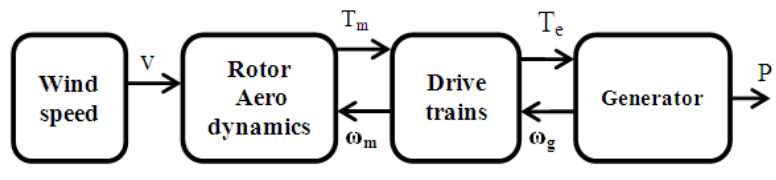

Fig. 1. Wind Turbine Scheme

\subsection{Wind Power Classification}

Wind turbines may be classified according to the range of wind speed at which they operate. Table 1 gives wind power classification at $50 \mathrm{~m}$ hub height.

Table 1. Wind Power Classification

\begin{tabular}{|c|c|c|c|c|}
\hline $\begin{array}{l}\text { Wind } \\
\text { Power } \\
\text { Class } \\
\end{array}$ & $\begin{array}{l}\text { Resource } \\
\text { Potential }\end{array}$ & $\begin{array}{l}\text { Wind Power } \\
\text { Density at } \\
50 \mathrm{~m}\left(\mathrm{~W} / \mathrm{m}^{2}\right)\end{array}$ & $\begin{array}{l}\text { Wind } \\
\text { Speed at } \\
50 \mathrm{~m}(\mathrm{~m} / \mathrm{s})\end{array}$ & $\begin{array}{l}\text { Wind } \\
\text { speed at } \\
50 \mathrm{~m}(\mathrm{~m} / \mathrm{h})\end{array}$ \\
\hline 1 & Poor & $0-200$ & $0.0-6.0$ & $0.0-13.4$ \\
\hline 2 & Marginal & $200-300$ & $6.0-6.8$ & $13.4-15.2$ \\
\hline 3 & Fair & $300-400$ & $6.8-7.5$ & $15.2-15.8$ \\
\hline 4 & Good & $400-500$ & $7.5-8.1$ & $15.8-18.1$ \\
\hline 5 & Excellent & $500-600$ & $8.1-8.6$ & $18.1-19.3$ \\
\hline 6 & Outstanding & $600-800$ & $8.6-9.5$ & $19.3-21.3$ \\
\hline 7 & Superb & $>800$ & $>9.5$ & $>21.3$ \\
\hline
\end{tabular}

\subsection{Wind Farms}

A wind farm is a collection of wind turbines in the same location and used for large scale generation of wind power electricity usually hundreds of megawatts. The process of integrating several individual wind turbines at a common bus to get a common output is usually referred to as wind harvesting. Either the consumers (for a stand-alone system) or the utility grid is fed from the wind bus via a main stepup transformer.

\section{Materials and Methods}

In this research, the procedures taken for site location and operation of a viable wind farm in Owerri for distributed generation include: Site selection; resource assessment and data Collection; establishment of requisite turbine models for the exploitation of the wind energy; simulation of the wind turbine to evaluate generated power and system performance; and integration of the wind resource with the utility/grid network.

\subsection{Site Selection}

Points considered for selecting a site for wind farm installation include:

- Open Space: The installation of a wind power generating station requires open space availability.

- Consistently bent trees and vegetation: this is a sure sign of strong wind regime in any given area.

- Accessibility: A site chosen for wind farm installation must be one with accessibility for construction, monitoring, maintenance, and power transmission.

During the site visit, other purposes to be borne in mind include:

- Check for potential site constraints;

- Permission for the wind plant or its transmission lines;

- Probable local land owners' resistance to selling the necessary land and easements;

- Availability of possible location for a wind monitoring station.

\subsection{Wind Resource Assessment / Data Collection}

The wind data used in this study were obtained from the Nigerian Meteorological Agency, Oshodi, Lagos. The data was captured by direct measurement at Latitude (N) $5^{\circ} 29 \square$ and Longitude (E) $7^{\circ} 02 \square$ at a height of $10 \mathrm{~m}$ by a cupgenerator anemometer. The data collection spanned a period of 11 years $(2000-2011)$. The recorded wind speeds were computed as the mean of the speed for each month. The site wind speed parameters considered for the wind resource assessment of Owerri include the mean wind speed, most probable wind speed, wind speed carrying maximum energy, mean wind power density, mean energy density and mean power output and capacity factor of the selected site.

\subsection{Mathematical Expressions for the Wind Energy Parameters}

Mean wind speed (MWS) is the most commonly used indicator of wind production potential. The mean wind speed is defined as [5]:

$$
\mathrm{MWS}=\frac{1}{N} \sum_{I=N}^{i-N} \mathrm{~V}_{i}
$$

Where $\mathrm{N}$ is the sample size and Vi the speed recorded for $\mathrm{i}^{\text {th }}$ observation.

The most probable wind speed indicates the wind speed with most probable occurrence for the period under investigation. It could be estimated using the formula [5].

$$
\mathrm{V}_{\mathrm{F}}=C\left(\frac{K-1}{K}\right)^{\frac{1}{K}}
$$

Where $C$ is the Weibull scale parameter in $\mathrm{m} / \mathrm{s}$ and $\mathrm{K}$ is the dimensionless Weibull parameter also called form factor

The wind speed carrying maximum energy can be used 
to estimate the rated wind speed of the wind turbine. This parameter is estimated by the formula [5]

$$
\mathrm{V}_{\mathrm{E}}=C\left(\frac{K+2}{K}\right)^{\frac{1}{K}}
$$

The weibull scale parameter, $\mathrm{C}$ and the form factor $\mathrm{K}$ are defined as [6]:

$$
\mathrm{C}=\frac{\mathrm{V}_{\mathrm{m}}}{\left(1+k^{-1}\right)}
$$

At any other given height, $h, C(h)$ could be extrapolated using the equation [6]:

$$
\mathrm{C}(\mathrm{h})=\mathrm{c}_{\mathrm{o}}\left(\frac{\mathrm{h}}{\mathrm{ho}}\right)^{n}
$$

Where

$$
\begin{gathered}
\mathrm{n}=\frac{[0.37-0.088 \ln (\mathrm{Co})]}{\left[1-0.088\left(\frac{\mathrm{h}}{10}\right)\right]} \\
\mathrm{k}=\left(\frac{\sigma}{\mathrm{V}_{\mathrm{m}}}\right)^{-1.086}
\end{gathered}
$$

and $\mathrm{V}_{\mathrm{m}}$ is the mean wind speed, $\square$ is a gamma function, and $\sigma$ is the standard deviation.

To determine value of $\mathrm{K}$ at a new height, $\mathrm{h}$, the same formula for extrapolation of $\mathrm{C}(\mathrm{h})$ applies, with only difference in substituting $\mathrm{K}$ for $\mathrm{C}$.

The mean wind power density can be estimated by the equation:

$$
\mathrm{P}_{\mathrm{D}}=\frac{\mathrm{P}_{(\mathrm{v})}}{\mathrm{A}}=0.5 \rho \mathrm{V}_{\mathrm{m}}
$$

where $P_{(V)}$ is the wind power (in watt), $P_{D}$ is the wind power density (watt per square meter), $\rho$ is the air density at the site (assumed to be $1.225 \mathrm{~kg} / \mathrm{m}^{3}$ in this study) and $\mathrm{A}$ is the swept area of the rotor blades (in square meter).

Also, based on the Weibull probability density function,

$$
P_{D}=\frac{P_{(v)}}{A}=0.5 \rho C^{3}\left(1+\frac{3}{k}\right)
$$

The mean energy density $\left(\mathrm{E}_{\mathrm{D}}\right)$ over a period of time $\mathrm{T}$ is the product of the mean power density and the time $\mathrm{T}$. It is expressed as:

$$
\mathrm{E}_{\mathrm{D}}=0.5 \rho \mathrm{C}^{3} \square\left(1+\frac{3}{\mathrm{k}}\right) \mathrm{T}
$$

Both the mean wind speed and the power density are generally used to classify wind energy resource.

The performance of a wind turbine installed in a given site can be examined by the amount of mean power output over a period of time $\left(\mathrm{P}_{\mathrm{e}, \mathrm{ave}}\right)$ and the conversion efficiency or capacity factor $\left(C_{f}\right)$ of the turbine. These are given by the equations [7]:

$$
\mathrm{P}_{\mathrm{e}, \mathrm{ave}}=\mathrm{P}_{\mathrm{e}, \mathrm{R}}\left(\frac{e^{-\left(\frac{V_{c}}{C}\right)^{k}}-e^{-\left(\frac{V_{r}}{C}\right)^{k}}}{\left(\frac{v_{r}}{c}\right)^{k}-\left(\frac{v_{c}}{c}\right)^{k}}\right)-e^{-\left(\frac{V_{f}}{C}\right)^{k}}
$$

$$
\mathrm{C}_{\mathrm{f}}=\frac{\mathrm{P}_{\mathrm{e}, \mathrm{ave}}}{\mathrm{P}_{\mathrm{e}, \mathrm{R}}}
$$

Where $V_{c}, V_{r}$ and $V_{f}$ are the cut-in wind speed, rated wind speed and cut-off wind speed, respectively. For an investment to be cost effective, it is expected that the capacity factor, $\mathrm{C}_{\mathrm{f}}$ be greater than 0.25 . It should be noted that the cost of generating electricity using wind turbine is inversely proportional to the capacity factor. The higher the capacity factor (or higher wind speed regime), the lower the cost of generated electricity, assuming that all factors remain the same [4].

Wind speed near the ground changes with height. The most common expression for the variation of wind speed with height is the power law expressed as follow [7]:

$$
\frac{v_{2}}{v_{1}}=\left(\frac{h_{2}}{h_{1}}\right)^{\alpha}
$$

Where $v_{2}$ and $v_{1}$ are the mean wind speeds at heights $h_{2}$ and $h_{1}$ respectively and the exponent, $\alpha$ is the surface roughness coefficient, which depends on factors such as surface roughness and atmospheric stability.

The surface roughness coefficient (Hellman's constant) can be gotten by the expression [8]:

$$
\alpha=\frac{\left[0.37-0.088 \ln \left(v_{1}\right)\right]}{\left[1-0.088\left(\frac{h_{1}}{10}\right)\right]}
$$

For Owerri, the value is about 0.2713 .

\subsection{Modeling of the Wind Turbine}

With respect to this study, only the blade model of the wind turbine will be considered. The wind turbine blades extract the kinetic energy in the wind and transform it into mechanical energy. The following parameters are considered for modeling of the wind turbine blade:

(a) Kinetic Energy in the Air

The kinetic energy of an object of mass $m$ moving in air with speed $v$ is equal to:

$$
\mathrm{E}=\frac{1}{2} m v^{2}
$$

The power in the moving air (assuming constant speed) is equal to:

$$
P_{w}=\frac{\mathrm{dE}}{\mathrm{dt}}=\frac{1}{2} m v^{2}
$$

Where, $m$ is the mass flow rate per second.

\section{(b) Wind Power Density}

The wind resource of the location of a wind farm is calculated using a model of the wind power density. It is the amount of energy available from the wind. There are three factors needed for this model, which are: area of the turbine blades; density of the air; and the wind velocity of the location.

The power of the wind $\mathrm{P}_{(\mathrm{v})}$ at speed $v$ through a blade sweep area A, increases with the cube of its velocity and is given as: 


$$
P_{(v)}=\frac{1}{2} \rho A V^{3}
$$

Where $\rho$ is the mean air density assumed to be 1.225 $\mathrm{kg} / \mathrm{m}^{3}$ in this study at average pressure of sea level and at $25^{\mathrm{O}} \mathrm{C}$.

\subsection{Wind Farm Interconnection / Grid Integration}

The aggregated power output of a given wind farm could either be utilized as a stand-alone scheme, where the wind farm directly feeds the consumers, or it could be interconnected with the utility grid at a $415 \mathrm{~V}$ distribution substation busbars for power augmentation [3].

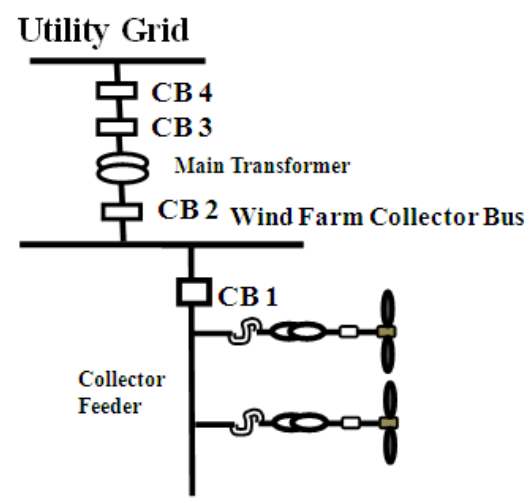

Fig. 2. Principal layout of a typical wind Farm system

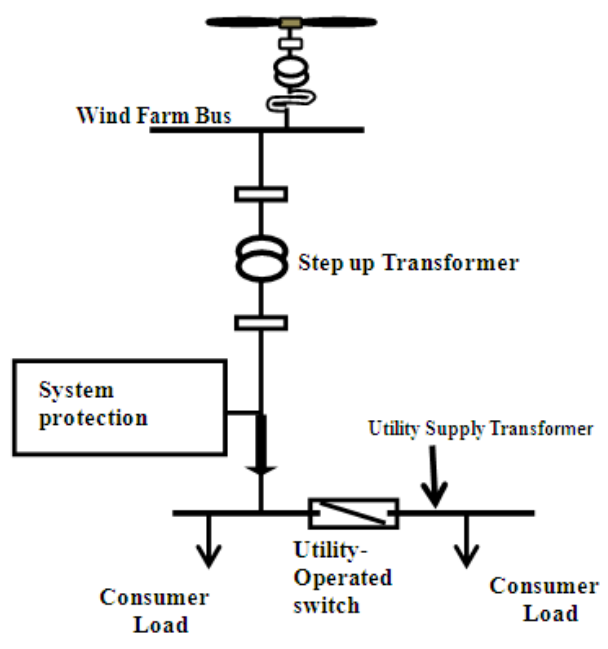

Fig. 3. Network interconnection incorporating a protection circuit

Figs. 2 and 3 show the layout of a typical wind farm grid interconnection and a network incorporating protection scheme.

The wind turbo-generators are connected to collector feeders through circuit breakers and local transformers with fuses. Several collector feeders are connected through feeder circuit breakers CB-1 to a point of common coupling, PCC, which is the collector bus or wind farm bus. The aggregated output of the wind farm is then connected to the grid bus via collector bus circuit breaker CB-2, a main step up transformer, which matches the wind farm voltage to the grid voltage, transformer breaker CB-3 and bus breaker CB-4.

\subsection{System Operation and Protection}

The characteristic variability associated with wind speed results in variable output power of the wind farm. There may arise occasions where the wind speed is so low (lower than the turbines' cut-in wind speeds). Under such conditions, there will be no power output from the wind turbines. In such occasions, possibility of power flowing from the utility to the wind farm is very high if there is no protection against such. This situation is detrimental to the wind machines. Also, there will arise occasions where there is no utility supply. The entire load will have to be carried by the wind output. This could also result to overloading of the wind farm, which will damage the installation. Another issue that may also arise is that of islanding, where the DG source may continue to feed a part of the network in the absence of grid supply. This will pose a dangerous threat to utility workers who may not realize that a circuit is still 'live' while attempting to work on the network.

To avoid such incidence, Fig. 3 becomes very necessary for the interconnection. A protection circuit that ensures a safe, efficient and reliable operation is incorporated in the interconnection network of the DG and the grid.

The synchroscope (an electronic device for synchronization) is utilized to synchronize the wind farm with the grid once the frequency, voltage magnitude, phase angle and phase sequence of both utility busbars and wind farm output are the same. If on the course of operation of the system, the wind farm falls short of any of these conditions, the synchroscope quickly disconnects it to prevent damage. Reverse power protection scheme ensures that power continuously flow in one direction, from the wind farm to the grid bus and not vice versa.

\section{Results and Discussion}

The Tables 2, 3, $4 \& 5$ and Figs. 4, $5 \& 6$ show the detailed presentations of results obtained on the wind energy potentials of Owerri; while Fig. 7 shows the simulated power output with varying wind and generator speeds [9].

Table 2. Eleven years measured monthly mean wind speed data of Owerri

\begin{tabular}{ll}
\hline MONTH & $\mathbf{1 0 m}$ height \\
\hline January & 3.52 \\
February & 3.54 \\
March & 3.64 \\
April & 3.70 \\
May & 3.45 \\
June & 3.55 \\
July & 3.32 \\
August & 3.42 \\
September & 3.31 \\
October & 3.04 \\
November & 2.67 \\
December & 3.00 \\
Annual & 3.35 \\
\hline
\end{tabular}


Table 3. Characteristic speeds and mean power density in Owerri at a height of $10 \mathrm{~m}$

\begin{tabular}{llllllll}
\hline $\begin{array}{l}\text { MON } \\
\text { TH }\end{array}$ & $\begin{array}{l}\mathbf{V}_{\mathbf{m}} \\
(\mathbf{m} / \mathbf{s})\end{array}$ & $\mathbf{K}$ & $\begin{array}{l}\mathbf{C} \\
(\mathbf{m} / \mathbf{s})\end{array}$ & $\begin{array}{l}\mathbf{V}_{\mathbf{F}} \\
(\mathbf{m} / \mathbf{s})\end{array}$ & $\begin{array}{l}\mathbf{V}_{\mathbf{E}} \\
(\mathbf{m} / \mathbf{s})\end{array}$ & $\begin{array}{l}\mathbf{P}_{\mathbf{D}} \\
\left(\mathbf{W} / \mathbf{m}^{2}\right)\end{array}$ & $\begin{array}{l}\mathbf{E}_{\mathbf{D}} \\
\left(\mathbf{k W h} / \mathbf{m}^{2}\right)\end{array}$ \\
\hline Jan. & 3.52 & 2.61 & 3.96 & 3.29 & 4.92 & 26.71 & 19.234 \\
Feb. & 3.54 & 8.11 & 3.74 & 3.68 & 3.84 & 27.17 & 19.564 \\
Mar. & 3.64 & 7.00 & 3.87 & 3.79 & 4.02 & 29.54 & 21.269 \\
Apr. & 3.70 & 6.61 & 3.96 & 3.87 & 4.12 & 31.02 & 22.338 \\
May & 3.45 & 8.48 & 3.63 & 3.58 & 3.72 & 25.15 & 18.109 \\
Jun. & 3.55 & 8.46 & 3.74 & 3.68 & 3.83 & 27.40 & 19.730 \\
Jul. & 3.32 & 6.30 & 3.56 & 3.47 & 3.72 & 22.41 & 16.138 \\
Aug. & 3.42 & 5.30 & 3.72 & 3.57 & 3.95 & 24.50 & 17.641 \\
Sep. & 3.31 & 7.01 & 3.53 & 3.45 & 3.66 & 22.21 & 15.993 \\
Oct. & 3.04 & 5.41 & 3.30 & 3.17 & 3.49 & 17.21 & 12.390 \\
Nov. & 2.67 & 6.28 & 2.97 & 2.88 & 3.10 & 11.66 & 8.394 \\
Dec. & 3.00 & 4.80 & 3.28 & 3.12 & 3.35 & 16.54 & 11.907 \\
Annual & 3.36 & 5.10 & 3.65 & 3.50 & 3.90 & 23.23 & 203.530 \\
\hline
\end{tabular}

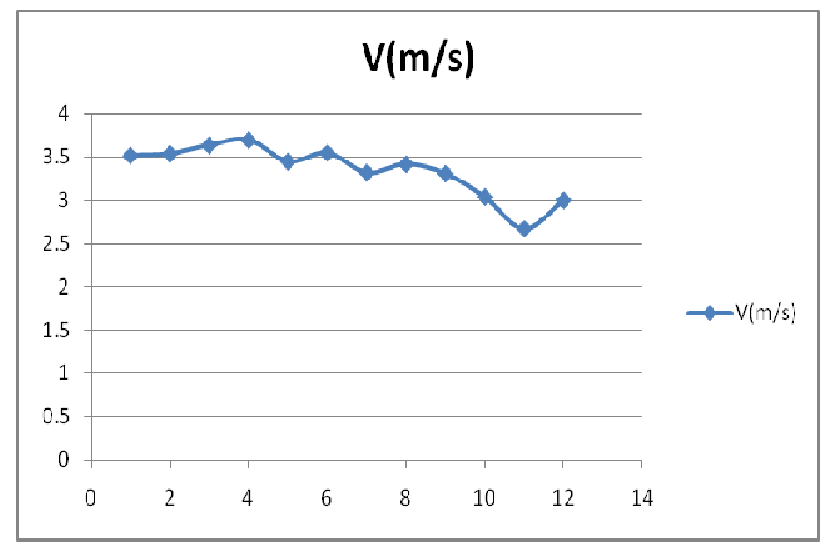

Fig. 4. Monthly variation of the mean wind speed at $10 \mathrm{~m}$ height.

Table 4. Extrapolated monthly mean wind speeds at varying heights

\begin{tabular}{llll}
\hline Month & 30m height & $\mathbf{5 5 m}$ height & 70m height \\
\hline January & 4.74 & 5.60 & 5.98 \\
February & 4.77 & 5.62 & 6.00 \\
March & 4.90 & 5.78 & 6.17 \\
April & 4.98 & 5.88 & 6.27 \\
May & 4.65 & 5.48 & 5.85 \\
June & 4.78 & 5.64 & 6.02 \\
July & 4.47 & 5.27 & 5.63 \\
August & 4.61 & 5.43 & 5.80 \\
September & 4.46 & 5.26 & 5.61 \\
October & 4.10 & 4.83 & 5.15 \\
November & 3.60 & 4.24 & 4.53 \\
December & 4.04 & 4.76 & 5.09 \\
\hline
\end{tabular}

Table 5. Monthly mean wind speed with power density variations of Owerri at $50 \mathrm{~m}$ hub hub height

\begin{tabular}{lll}
\hline Month & Mean Wind Speed $(\mathbf{m} / \mathbf{s})$ & Power Density $\left(\mathbf{W} / \mathbf{m}^{2}\right)$ \\
\hline January & 5.45 & 99.15 \\
February & 5.48 & 100.8 \\
March & 5.63 & 109.30 \\
April & 5.73 & 115.23 \\
May & 5.34 & 93.27 \\
June & 5.50 & 102 \\
July & 5.14 & 83.18 \\
August & 5.29 & 90.67 \\
September & 5.12 & 82.21 \\
October & 4.70 & 63.59 \\
November & 4.13 & 43.15 \\
December & 4.64 & 62.38 \\
Annual & 5.20 & 86.124 \\
\hline
\end{tabular}

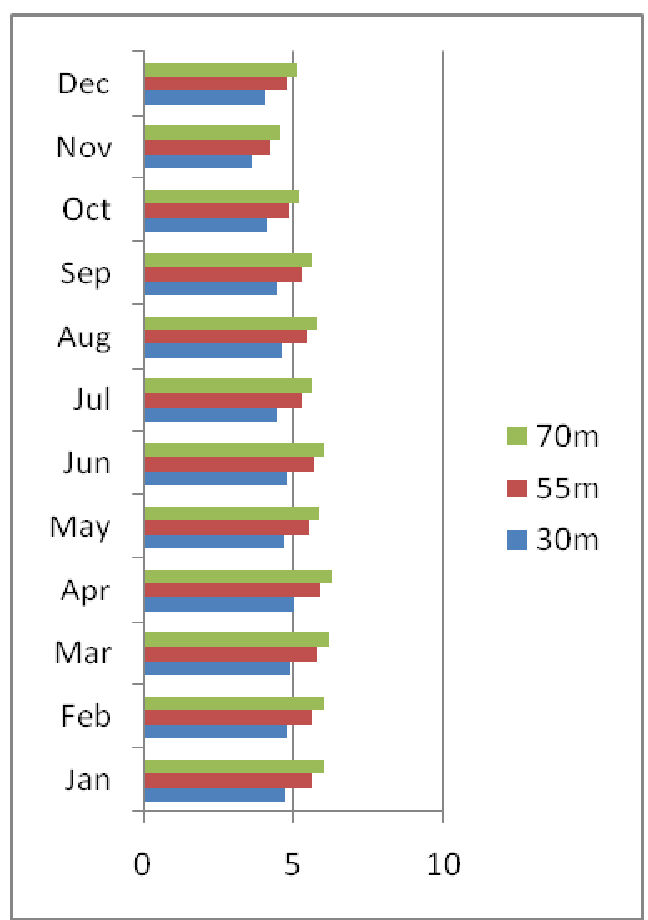

Fig. 5. Chat of monthly mean wind speed changes at 30m, $50 \mathrm{~m} \& 70 \mathrm{~m}$ heights

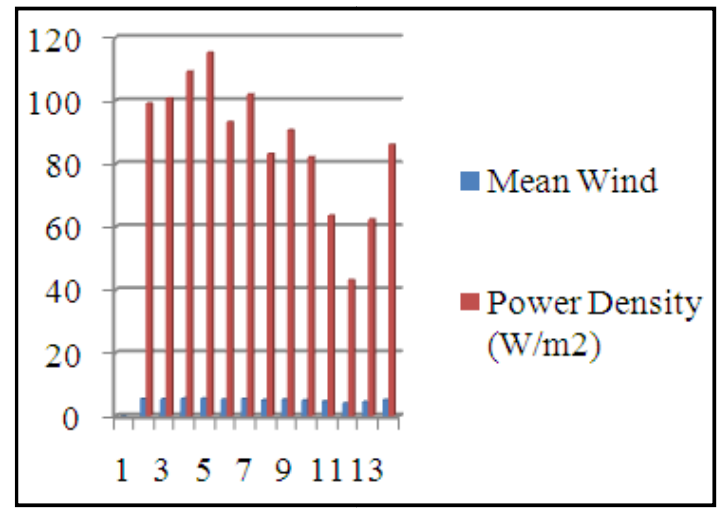

Fig. 6. Mean wind speed with power density variation in Owerri at $50 \mathrm{~m}$ hub height 


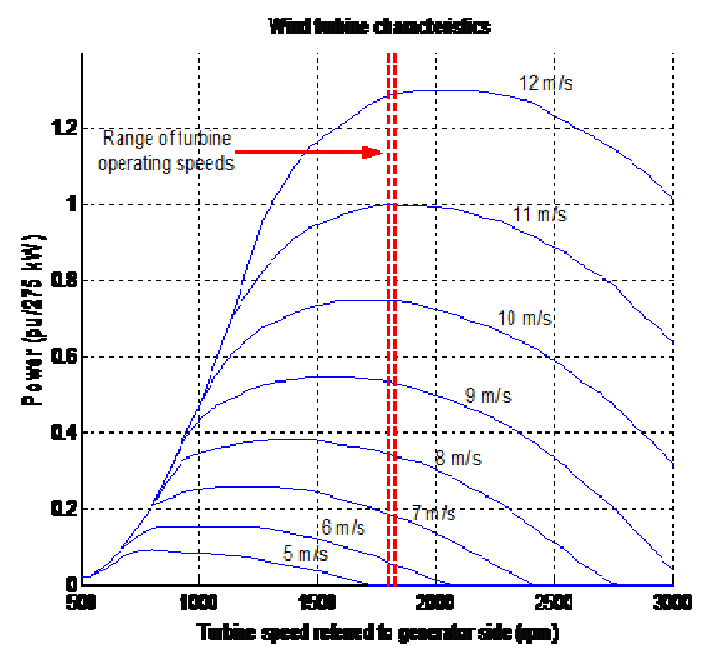

Fig. 7. Turbine power output with varying wind and generator speeds.

(a) Owerri Wind Resource Potential:

The monthly variation of the mean wind speed at $10 \mathrm{~m}$ height and the extrapolations at $30 \mathrm{~m}, 55 \mathrm{~m}$ and $70 \mathrm{~m}$ are presented in Tables 2 and 4 and Figures 4 and 5 respectively.

Table 3 contains detailed information about the wind speed characteristics (mean wind speed $\mathrm{V}_{\mathrm{m}}$, most probable wind speed $\left(\mathrm{V}_{\mathrm{F}}\right)$ and the wind speed carrying maximum energy $\left(\mathrm{V}_{\mathrm{E}}\right)$ ) and mean power density, while Table 5 contains estimated values of mean wind speeds and power densities at $50 \mathrm{~m}$ hub height.

The monthly mean wind speed varies between $2.67 \mathrm{~m} / \mathrm{s}$ in November and $3.70 \mathrm{~m} / \mathrm{s}$ in April at $10 \mathrm{~m}$ height and the corresponding monthly mean power density varies between $11.65 \mathrm{~W} / \mathrm{m}^{2}$ and $31.02 \mathrm{~W} / \mathrm{m}^{2}$ respectively. This shows that any wind farm installed in Owerri will have its minimum and maximum outputs in the months of November and April respectively.

Based on the wind power classification scheme in Table 1 , and referring to Table 5, the monthly mean power density for Owerri falls into the Class-1 wind resource category $\left(P_{D} \leq 100\right)$ for all the months and the annual mean power density is $23.23 \mathrm{~W} / \mathrm{m}^{2}$ at $10 \mathrm{~m}$ hub height and $86.12 \mathrm{~W} / \mathrm{m}^{2}$ (Class 1) at $50 \mathrm{~m}$ height. It therefore follows that Owerri has poor wind resource potential.

(b) Form Factor $\mathrm{K}$ and the scale factor $\mathrm{C}$ :

The form factor, K, shows the degree of uniformity of the wind resource. The least monthly value of this Weibull shape parameter for Owerri is 2.61 in January and it reached the highest value of 8.48 in the month of May. Therefore, the wind speed is most uniform in Owerri in May, while it is least uniform in January. This indicates least variability of output power in the month of May and most variability in January.

The annual form factor for Owerri is 5.10. The least monthly value of Weibull scale parameter $\mathrm{C}$ is obtained as $2.97 \mathrm{~m} / \mathrm{s}$ in the month of November in Owerri, and the highest value of $3.96 \mathrm{~m} / \mathrm{s}$ in the months of January and April. The annual value is $3.65 \mathrm{~m} / \mathrm{s}$. (c) Power Output of a turbine:

A simulated $275 \mathrm{KW}$ rated turbine at various wind speeds $(\mathrm{m} / \mathrm{s})$ and generator operating speeds $(\mathrm{rpm})$ gave the graph of Fig 7. Keeping all design parameters constant, the power that can be generated at any given wind speed can be easily computed using the graph.

\section{Conclusion and Recommendations}

In this paper, the use of wind for distributed generation as a means of augmenting the utility grid in Owerri has been considered and detailed wind data analysis for Owerri carried out in order to investigate the wind resource potential. Wind energy models used in the investigation were equally presented alongside the possible DG/grid network interconnections/integration. The findings show that the annual mean wind speed of Owerri at $10 \mathrm{~m}$ hub height is $3.36 \mathrm{~m} / \mathrm{s}$ and the annual mean wind speed carrying maximum energy is $3.9 \mathrm{~m} / \mathrm{s}$. The annual mean power density is $23.23 \mathrm{~W} / \mathrm{m}^{2}$. At $50 \mathrm{~m}$ hub height, the annual mean power density is $86.124 \mathrm{~W} / \mathrm{m}^{2}$. The deduction from the Wind Power Classification of Table 1, implies that the wind energy resource of Owerri falls into Class 1, an indication of poor wind regime.

\subsection{Recommendations}

Utilizing wind for power generation in Owerri at a large scale (either for grid integrated or stand alone scheme) will not be feasible, as the investor will incur huge losses, since the power out is going to be low and return for investment negative.

However, the wind in this city could be used for small scale applications such as water pumping, windmills, and other applications requiring small amount of power.

\section{References}

[1] A.S. Sambo, "Renewable Energy option for sustainable development", Paper presented at the Renewable Electricity Policy Conference held at Shehu Musa Yar'adua Centre, Abuja, pp. 11-12, 2006.

[2] R. O. Fagbenle, J. Katende, O. O. Ajayi, \& J. O. Okeniyi, "Assessment of wind energypotential of two sites in NorthEast", Nigeria. Journal of Renewable Energy, 36, pp. 12771293, 2011.

[3] J. Martinez, "Modelling and Control of Wind Turbines. Imperial College”, London, pp. 11 - 41, 2007.

[4] S. S. Paul, S. O. Oyedepo, \& M. S. Adaramola, "Economic Assessment of Water-pumping Systems using Wind Energy Conversion Systems in the Southern Part of Nigeria", Energy Exploration and Exploitation 30, pp. 1-18, 2012.

[5] S. O. Oyedepo, M. S. Adaramola, \& S. S. Paul, "Analysis of wind speed data and wind energy potential in three selected locations in south-east Nigeria", International Journal of Energy and Environmental Engineering, pp. 2-4, http://www.journal-ijeee.com/content/3/1/7, 2012. 
[6] C. G. Justus, W. R. Hargraves, A. Mikhail, \& D. Graber, "Methods for estimating wind speed frequency distributions" Journal of Applied Meteorology, 17, 350-353, 1978.

[7] E. K. Akpinar \& S. Akpinar, "An assessment on seasonal analysis of wind energy characteristics and wind turbine characteristics", Energy Conversion and Management, Vol. 46, pp. 1848-1867, 2005.
[8] A. Ucar, \& F. Balo, "Evaluation of Wind Energy Potential and Electricity Generation at Six Locations in Turkey", Applied Energy, 86, 1864-1872, 2009.

[9] M. T. Lamchich \& N. Lachguer, "Matlab Simulink as Simulation Tool for Wind Generation Systems Based on Doubly Fed Induction Machines", pp. 145. Available online at http://dx.doi.org/10.5772/48774, 2013. 